\title{
The New Deal - freedoms, experiments, sustainability. The road ahead
}

\author{
Paul Evans \\ Senior vice president - publishing and research relations, Elsevier
}

\section{Main presentation}

With a new president in the USA it seems now more than the ever is the importance, in a gathering recession, to build optimism but also to do this with some pragmatism and realism. The expression, Yes we can, applies to the academic publishing world and we must all learn better how to "accentuate the positive", as the famous song describes it.

Innovation is the positive that needs to be accentuated by publishers. Publishers have always innovated but especially in the digital era. In recent years in academia new dissemination models have arisen from a variety of players but this is not the only area of innovation and attention should be placed across different areas of customer concerns and ways of meeting their needs.

Explicit reactions to the new models mentioned have stressed some of the scepticism over financial viability of certain models. Also publishers have stressed risks to quality in the adoption of new models. However, some of the anxiety expressed by publishers may be misplaced as if the mainly successful system of subscriptions could be under threat of collapse from those who have voiced opposition or posited alternatives. This seems unlikely unless alternatives are pragmatic and really work in practice; with many new innovations taking place across our industry it seems a healthy environment for experimentation while not risking the whole system on a single way forward.

There have also been some tacit concerns in the recent era where it has to be said that some of the alternatives had been driven less by an awareness of a technological opportunity and more by a mistrust of publishers due to the discomfort experienced by customers with the history of price rises particularly in the predigital era.

In conclusion there is a risk for publishers of being too defensive in approach as of seeming to slow down the pace of innovation which is of course not the case. Publishers do need to coordinate better across the research world and to demonstrate value together as a community especially in the wake of the current financial crisis where all areas of the economy come under scrutiny but few are so essential for the future as the outputs of research.

The record of innovation at Elsevier as one example from the industry is very strong. In the 1990s there was a high level of digital transformation with the emergence of technology platforms for delivering text. This era brought new technology, new strategies and new people in the post dotcom bubble where many pioneers moved to more reliable business models and businesses for investment of their talent and efforts. 
In the UK just over 15 years ago I was responsible for Elsevier's systems capability with just six staff in total. Now there are hundreds in technology related functions and offshored resources include for example all the helpdesk functions managed from India in part of a globalised operation.

Journal related publishing investments have exceeded 300 million Euros with investments not just in Science Direct (the largest investment) but in the supporting electronic warehouse and electronic workflow management, production tracking systems, provision of backfiles (which alone cost around 40 million dollars) as well as Elsevier editorial systems to aid electronic submission and support for editing and refereeing processes.

The record of innovation across the STM industry has been strong. Around 7\% of papers allow for delayed access as at the journal Cell for example where content is free after 12 months. Sponsored access accounts for between 1 and $2 \%$ of papers and this has been beneficial for funding bodies who have made arrangements with publishers (e.g. the Wellcome Trust).

The Research4Life programme has enabled authors in poorer countries to make use of systems and journals for a large number of publications including ones in health, agriculture and the environmental areas (HINARI, AGORA and OARE with UN/WHO agencies).

Open peer review experiments have been tried, for example at Nature. Perhaps some of this experience was premature but it will continue to be examined in the industry.

There has been increased use of moderated conferencing and of social bookmarking (as with Elsevier's 2Collab service). There have also been some more liberal posting policies so that authors can put their papers on their institutional repositories without the need to request permission in many cases.

Natural language processing engines have come into use to make research and discovery tools as with Elsevier's new service for corporate markets, Illumin8 enabling users to find related organizations, products, experts, approaches as well as research findings.

In the case of Elsevier there has been a whole roadmap of initiatives accompanying the experimentation with new dissemination models including cooperation with NIH, the Wellcome Trust, a sponsored article programme for certain journals, agreements with many other funding bodies as well as a landmark agreement with MIT on including Elsevier material in OpenCourseWare.

So in this new era there are signs of a new deal based on this background of healthy innovation which is the lifeblood of the industry and its benefits based on the energy and dynamism of private public partnerships. This new deal can address not just the 1 or 2 per cent of research funding spent on information services but also begin to address benefits to make greater efficiency in the core research budget area - the other $98 \%$ or so. And for publishers to do so helps support the value of research better overall. This perhaps is best shown in the emergence of the research performance visualiser (RPV) capability Elsevier has been experimenting with to help decision makers in research institutions and even economies based on an aggregation of citation data. The data is presented in a map form and enables decision makers to see where they are investing and also what results they are getting. Greater transparency has to be a benefit even if it will of itself not replace wise and prudent decision making by seasoned experts.

Greater efficiency of science and research is vital. But also this is not a time to reduce resourcing. The president of Mexico last year, noting the financial crisis, saw this as a justification to invest more in research not less as it provided a basis for the future economic activity of nations.

We have a responsibility as part of the research community working together to be able better to influence governments and avoid short termism at this time. Hence we should influence the pursuit of long term problems such as related to energy and the environment. We should also do our best to ensure the building blocks of science are being developed with basic research not just applied areas. 
As regards knowledge we should be sure to show that abstract notions of freedom need to engage with reality. Freedom of knowledge cannot persist without sustainable business models. Free in this case means "libre" rather than necessarily "gratuit" as there is always a cost somewhere to take care of. The defence of academic freedom is however vital, for governments should never have control of all research output and knowledge generation in case they impede progress in any area due to ideological concerns. And another freedom to cherish and broadcast is the freedom of knowledge enterprise. This is relevant not just for commercial enterprises making robust investments and platforms but for social enterprise and for societies of scientists bringing their benefits to their communities. Here innovation and enterprise are vital and can prevent risks of stagnation and fragmentation in the information arena.

So there are many lessons for us in this new era and also arising from the PEER experiment which many of you know. It is an EU supported initiative to test periods of time before papers are placed on repositories and to test the effects of usage, etc. Participants include publishers coordinated by the STM organization, research organizations and libraries. It is an ecological observatory for research publishing.

The benefits of such experiment and such a collaboration between these different stakeholders applies well to new areas of innovation to make practicable working models. Also however we can go further with this type of collaboration to work together to better influence government to recognize the value creating process of research and its related knowledge industries.

In conclusion, a publishing world without innovation can only lead to stagnation and likely decline. Innovation needs nurturing to ensure a successful mixed economy of players working together, experimenting and investing in new solutions for research overall.

The publishing world must work closely within the research community and play its role in securing overall support from government especially in times of financial crisis. And we should all be sensitive to the ecology of the research environment including the STM publishing world as at the end of the day it is probably evolution rather than the discontinuities of revolution that will win the day for the customer. We can thus say, "Yes we can... and we already do! Let's do more.". 